\title{
O CURRÍCULO NO CONTEXTO DA SOCIEDADE CONTEMPORÂNEA SOB A PERSPECTIVA DE PROFESSORES DA EDUCAÇÃO BÁSICA
}

THE CURRICULUM IN CONTEMPORARY SOCIETY CONTEXT UNDER THE PERSPECTIVE OF BASIC EDUCATION TEACHERS

EL CURRÍCULO EN EL CONTEXTO DE LA SOCIEDAD CONTEMPORÁNEA BAJO LA PERSPECTIVA DE PROFESORES DE LA EDUCACIÓN BÁSICA

\section{RESUMO}

Adriana Regina de Jesus Santos ${ }^{\mathbf{i}}$ Rogerio da Costa

O presente artigo tem como objetivo analisar as percepções dos professores da educação básica em relação ao entendimento sobre currículo no contexto da sociedade contemporânea. Para a realização deste estudo, utilizamos como pressupostos teórico e metodológico à abordagem qualitativa. Sendo assim, foi desenvolvido uma pesquisa bibliográfica, documental e de campo. A coleta de informações se deu por meio de questionário e de uma entrevista semiestruturada. Os resultados indicam que os professores apresentam uma certa dificuldade em conceituar e compreender o currículo de maneira crítica e reflexiva. Entre as considerações finais, aponta-se para o fato de que o docente necessita perceber o currículo como um território a ser contestado, não restringindo-o apenas como um documento oficial que regulamenta as disciplinas a serem ministradas no âmbito escolar, pois este necessita ser considerado como um projeto de nação.

PALAVRAS-CHAVE: Prática pedagógica. Relação professor-aluno. Escola básica.

\begin{abstract}
This article aims to analyze the perceptions of teachers of basic education in relation to the understanding of curriculum in the context of contemporary society. For the accomplishment of this study, we use as theoretical and methodological assumptions the qualitative approach. Thus, a bibliographical, documentary and field research was developed. Information was collected through a questionnaire and a semi-structured interview. The results indicate that teachers present a certain difficulty in conceptualizing and understanding the curriculum in a critical and reflexive way. Among the final considerations, it is pointed out that the teacher needs to perceive the curriculum as a territory to be challenged, not restricting it only as an official document that regulates the disciplines to be taught at the school level, as it needs to be Considered as a nation project.
\end{abstract}

KEYWORDS: Pedagogical practice. Teacher-student relation. Basic school.

\section{RESUMEN}

El presente artículo tiene como objetivo analizar las percepciones de los profesores de la educación básica en relación al entendimiento sobre currículo en el contexto de la sociedad contemporánea. Para la realización de este estudio, utilizamos como presupuestos teórico y metodológico al abordaje cualitativo. Siendo así, se desarrolló una investigación bibliográfica, documental y de campo. La recolección de información se dio por medio de un cuestionario y de una entrevista semiestructurada. Los resultados indican que los profesores presentan una cierta dificultad en conceptualizar y comprender el currículo de manera crítica y reflexiva. Entre las consideraciones finales, se apunta al hecho de que el docente necesita percibir el currículo como un territorio a ser contestado, no restringiéndolo apenas como un documento oficial que regula las disciplinas a ser ministradas en el ámbito escolar, pues éste necesita ser considerado como un proyecto de nación.

PALABRAS CLAVE: La práctica pedagógica. Relación profesor-alumno. La escuela básica.

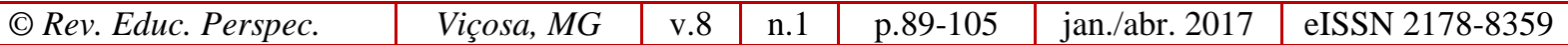




\section{INTRODUÇÃ̃o}

O presente artigo tem como objetivo analisar as percepções dos professores da educação básica em relação ao entendimento sobre currículo, tendo em vista o amplo campo de possibilidades que a escola oferece para pensar as práticas cotidianas como espaços/tempos da contemporaneidade.

Discutir aspectos que envolvem as instituições escolares, as práticas de ensino e o currículo escolar, requer um estranhamento acerca das questões políticas, econômicas, tecnológicas e de produção da existência que influenciam o contexto escolar. Tal exigência se deve ao fato de que "a educação é o processo pelo qual a sociedade forma seus membros à sua imagem e em função de seus interesses" (PINTO,1989, p. 29). Neste sentido, os aspectos relacionados à educação e ao currículo não devem ser percebidos de modo fragmentado, uma vez que necessitam abranger a totalidade de considerações, ou seja, perspectivas mais amplas que explicitem os fatos presentes no interior do espaço escolar como mais um fio de um emaranhado de acontecimentos sociais.

Destarte, a base metodológica deste estudo apoiou-se nos pressupostos da pesquisa qualitativa, pela possibilidade ofertada de investigar percepções acerca da natureza geral de uma questão, abrindo espaço para sua interpretação, de maneira que o objeto de estudo se torne parte integrante, repleto de significados e relações do sujeito que exerce a ação de investigação (CHIZZOTTI, 1995).

A coleta de informações na realidade foi realizada com 69 professores da educação básica em uma escola localizada na cidade de Londrina-PR. Os colaboradores apresentam faixa etária entre 22 e 62 anos, sendo que 29 deles são pedagogos que atuam na educação infantil e nos anos iniciais do ensino fundamental, 21 são professores de diversas áreas que atuam nos anos finais, 03 professores do ensino profissionalizante e 16 do ensino médio regular.

O questionário foi uns dos instrumentos utilizados para a coleta de dados, pois conforme instruções de Gil (1999) este é um dos instrumentos fundamentais, pois possibilita ao entrevistado afirmar e reafirmar conceitos acerca de uma determinada temática. Posteriormente, realizou-se uma entrevista semiestruturada com os professores, tendo como finalidade ampliar as informações obtidas, oferecendo espaço para que os colaboradores tratassem de assuntos previamente definidos, mediante um cenário de "conversa informal", fundamental quando se anseia mapear práticas, crenças, valores, representações de universos sociais específicos, em que os conflitos e contradições não se encontram abertamente explícitos (DUARTE, 2004). 
Faz-se necessário ressaltar que, as discussões recentes indicam que se espera que a escola, por meio do currículo, possibilite ao professor e aos alunos análises mais críticas e significativas da realidade em que estão inseridos. Para tanto, é necessário uma formação para além do senso comum, uma vez que, por meio desta, é possível desenvolver autonomia intelectual e consciência social diante dos fatos apresentados de forma tão naturalizada pela sociedade atual.

Isto posto, vemos que o currículo pode ser conceituado sob distintas maneiras e pontos de vista. Situação que também pode fazer com que o currículo seja entendido de forma fragmentada, pela qual é necessário juntar diversos "retalhos" para que possamos formar uma "colcha" e compreendê-lo em suas várias dimensões. É com base nestas considerações que evidenciamos, em nosso artigo, as representações conceituais que os professores, sujeitos de nossa pesquisa, tiveram acerca do currículo, são elas: disciplinas, conteúdos, norte, caminho, organização, conhecimento, noção de currículo, referência/formação pessoal e Projeto Político Pedagógico (PPP), como veremos a seguir.

\section{PERCEPÇÕES DOS PROFESSORES SOBRE O CONCEITO E O CONTEXTO DO CURRÍCULO}

A visão dos professores que fizeram parte do nosso estudo restringiu-se a um conceito de currículo fragmentado, não chegaram a um consenso de maneira ampla. Eles não perceberam o currículo pela sua constituição social, em que está diretamente relacionado a um período histórico que determina um ideal de sociedade e os conhecimentos necessários para se formar o sujeito neste contexto; classificaram o currículo subdividindo-o em partes.

Em um primeiro momento, vemos que $45 \%$ dos professores caracterizaram o currículo relacionando-o apenas a conteúdos, disciplinas, metodologia ou avaliação. Estes aspectos podem ser notados nos seguintes relatos:

São disciplinas e conteúdos desenvolvidos em sala de aula (Professor da Educação Infantil).

São conteúdos que precisam ser passados (Professor da Educação Infantil).

Currículo é o desenvolvimento e à avaliação de todas as atividades que serão propostas durante o período letivo (Professor da Educação Infantil).

Currículo é a organização dos conteúdos a ser trabalhados (Professor dos Anos Iniciais do Ensino Fundamental).

Currículo é o conjunto de disciplinas necessárias para o desempenho do aluno (Professor dos Anos Iniciais do Ensino Fundamental).

Currículo é o conteúdo das disciplinas de acordo com o nível de ensino (Professor dos Anos Finais do Ensino Fundamental).

n. 1

p.89-105


Curriculo é uma metodologias a ser aplicada e utilizada no processo educativo (Professor dos Anos Finais do Ensino Fundamental).

Currículo são disciplinas e conteúdos trabalhados na ação docente (Professor do Ensino Médio).

Currículo é o conjunto de métodos e conteúdos a serem aplicados em sala de aula (Professor do Ensino Médio).

Tendo como parametro as falas acima, ficou notório que grande parte dos professores pesquisados considera o currículo tão somente como grade de disciplinas e de conteúdos e, em menor número, aparecem metodologia e avaliação, mas que estão diretamente relacionadas ao ensino de conteúdos nas diferentes disciplinas, denotando uma aproximação com a teoria tradicional do currículo.

A Teoria Tradicional de currículo teve como base teórica os pressupostos de Tyler (1986) pois este defendeu o currículo como um instrumento de prescrição e controle, não levando em consideração as relações de poder e consequentemente as desigualdades presentes na sociedade, pois como podemos perceber pelos objetivos de Tyler (1986), a escola tem unicamente a função de transmitir uma cultura alicerçada na reprodução de pensamentos de uma determinada classe social, detentora do poder, consequentemente, o currículo é organizado para que o docente atue de maneira não reflexiva, isto é, executando ações baseadas apenas na forma como o mesmo foi, ou está estruturado.

De certo modo, esta é uma visão de currículo presente no imaginário dos professores, participantes deste estudo, principalmente quando estes apresenttam um pensamento fragmentado acerca do currículo onde fica visível uma não conexão entre as disciplinas no contexto escolar, colaborando, sobremaneira, para perceber o mesmo apenas como uma grade de disciplinas e seus respectivos conteúdos.

Sendo assim, é imprescindivel compreender que:

o currículo representa muito mais do que um programa de estudos, um texto em sala de aula ou o vocabulário de um curso que se traduzem nos conteúdos disciplinares. Mais do que isso, ele representa a introdução de uma forma particular de vida; ele serve, em parte, para preparar os estudantes para posições dominantes ou subordinadas na sociedade existente. O currículo favorece certas formas de conhecimento sobre outras e afirma os sonhos, desejos e valores de grupos seletos de estudantes sobre outros grupos (MCLAREN, 1997, p. 216).

É imprescindivel destacar que não podemos pensar o curriculo apenas no micro contexto escolar, como se a escola não fizesse parte de um panorama maior dentro da sociedade, pois este precisa estar relacionado a um saber contextualizado. Claro que estes procedimentos (disciplinas, conteúdos, metodologia, avaliação) também são importantes elementos curriculares para a formação humana, uma vez que por meio destes o saber é sistematizado,

\begin{tabular}{l|c|c|c|c|c|c|} 
(C) Rev. Educ. Perspec. & Viçosa, $M G$ & v.8 & n.1 & p.89-105 & jan./abr. 2017 & eISSN 2178-8359 \\
\hline
\end{tabular}


possibilitando assim, à apropriação do conhecimento pelos alunos. Portanto é necessario entender que o curriculo vai além das questões pedagógica, pois este implica conceitos de ideologia, cultura e relações de poder. Contribuindo com esta reflexão Silva e Hornburg (2007, p. 1) afirma que o curriculo esta relacionado a:

\begin{abstract}
questões de poder, tanto nas relações professor/aluno e administrador/professor, quanto em todas as relações que permeiam o cotidiano da escola e fora dela, ou seja, envolve relações de classes sociais (classe dominante/ classe dominada) e questões raciais, étnicas e de gênero, não se restringindo apenas a uma questão de conteúdos e suas respectivas disciplinas.
\end{abstract}

Ou seja, a citação acima evidencia que o currículo necessita ser refletido como uma variedade de processos que podem ser vivenciados pelo sujeito na sociedade, implicando indagar suas distintas perspectivas, seja social, política, econômica, cultural e pedagógica, pois só assim, poderemos compreender que o currículo é uma ferramenta de poder e de influência em um dado contexto histórico.

Desta forma, as discussões em torno do currículo necessitam ser ampliadas e aprofundadas para que a concepção fragmentada possa ser sobrepujada e o currículo passe a ser percebido tanto como um instrumento pedagógico quanto político, e que está repleto de intencionalidades explícitas e implícitas. A manifestação consciente desses aspectos faz com que o currículo, no ambiente escolar, seja vivenciado em diferentes níveis por meio da prática docente. Os relatos dos professores apresentados a seguir, apesar de não exibirem de forma explícita sua fragmentação, destacam esta conceituação de currículo.

\footnotetext{
O currículo envolve a concepção de conhecimentos que engloba a escola (Professor da Educação Infantil).

Caminhos para a prática (Professor da Educação Infantil).

Norteia nosso trabalho pedagógico (Professor da Educação Infantil).

Conhecimento sobre o que podemos ou não trabalhar com os alunos (Professor dos Anos Iniciais do Ensino Fundamental).

Caminho que leva ao conhecimento sistemático para formação do cidadão (Professor dos Anos Finais do Ensino Fundamental).

É o norteador de tudo o que deve ser trabalhado academicamente durante o período escolar (Professor do Ensino Médio).
}

De acordo com os discursos apontados, o conceito de currículo ficou caracterizado também como um norte, um caminho a ser percorrido ou um conhecimento a ser trabalhado. Dos $25 \%$ dos docentes que chegaram a esta conclusão, de certa maneira, embora apresentem um pensamento bastante conciso e não deixam de ter razão em suas reflexões, visto que estes princípios são basilares para a compreensão do currículo, podemos afirmar que suas representações deixam margem para muitos questionamentos, tais como: O currículo, nestas

n.1 1 p.89-105


percepções, é um norteador de qual conhecimento? Qual caminho seguir para chegarmos ao conhecimento quando pensamos em currículo?

Estas são só algumas considerações que emitimos para evidenciar que este entendimento suscita que o currículo é caracterizado em distintos planos quando pensamos no conhecimento que é proporcionado, já que este conhecimento pode acontecer por caminhos díspares, dependendo da finalidade, do norte que damos à educação. Neste panorama, o currículo se constitui em diferentes níveis no espaço escolar: o currículo prescrito, o currículo real e o currículo oculto (SILVA, 2010). Estes níveis de currículo irão determinar que o conhecimento, que será ou não apreendido pelos alunos, estará sujeito a uma série de eventualidades que perpassam a escola e a sociedade.

Ao destacarmos que, no espaço escolar, existem esses três níveis de currículo, compreendemos igualmente que o conhecimento a ser oferecido ao sujeito é inerente a um conjunto de valores e intenções de uma sociedade, a qual dita regras e concepções de educação socialmente válidas que devem ser materializadas na sala de aula. Esta solidificação do conhecimento que deve ser articulado na escola transcorre obrigatoriamente por intermédio do professor, ou seja, o docente será o artífice necessário para a concretização do currículo que será efetivado na sala de aula. Sob esta perspectiva de currículo, entendemos ser evidente a relação de poder,

que diferentes agentes têm sobre ele, intervindo, dessa forma, na distribuição do conhecimento dentro do sistema escolar e iniciando na prática educativa, enquanto apresenta o currículo a seus consumidores, ordenam seus conteúdos e códigos de diferentes tipos (SACRISTÁN, 2000, p. 109).

Nesta perspectiva, levando em consideração que vivemos em uma sociedade capitalista, a escola assume um papel estratégico tanto em consentir uma educação significativa para o sujeito como para impedi-la, definindo o lugar de cada um na sociedade. Esse aspecto poderá ser perceptível em distintos momentos no panorama escolar, determinando, assim, os diferentes tipos de currículo presentes na escola: o prescrito, o real e o oculto. Estes, consequentemente, determinam, valendo-se do trabalho docente, o norte e o caminho que o conhecimento irá acontecer.

Dito isto, é importante acrescentar que o currículo prescrito presente no sistema educativo é regulamentado por instituições político-administrativas, expressando, por exemplo, diretrizes curriculares, objetivos e conteúdos disciplinares. É clara a sua intenção de prescrição, ou seja, de "orientar" o que deve conter no currículo em relação à "educação obrigatória". Este tipo de currículo é extrínseco ao docente, por isso, como já foi notado em nossa pesquisa pelas representações dos professores, este instrumento se torna uma incógnita para muitos

n.1 1 p.89-105

jan./abr. 2017 1 eISSN 2178-8359


profissionais da educação, fazendo com que estes sujeitos não o entendam como um documento que possui muitas intencionalidades, contribuindo para um não juízo a respeito do currículo de maneira ampla. Assim, o currículo prescrito pode

ter escasso valor para articular a prática dos docentes, para elaborar atividades de ensino, ou para dar conteúdo concreto a objetivos pedagógicos, que, por muito específicos e por muita concreta que seja a sua definição, não podem transmitir ao professor o que é preciso fazer com os alunos, o que ensinar-lhes (SACRISTÁN, 2000, p. 122).

Por outro lado, o currículo real é aquele idealizado pela prática profissional do professor, é o modo como os conteúdos são proporcionados e contextualizados na sala de aula, ou seja, é aquilo que é posto em prática neste espaço. A materialização do currículo real na escola se dá particularmente na relação diária do professor com o aluno quando são efetivados os projetos pedagógicos, os planos de ensino (SILVA, 2010). Perrenoud (1995) entende que o currículo real é a maneira como se consolida, no cotidiano da escola, o currículo prescrito. Para este mesmo autor,

O currículo real nunca é a estrita realização de uma intenção do professor. As atividades, o trabalho escolar dos alunos escapa parcialmente ao seu controle, porque, no seu percurso didático, nem tudo é escolhido de forma perfeitamente consciente e, sobretudo, porque as resistências dos alunos e as eventualidades da prática pedagógica e da vida quotidiana na aula fazem com que as atividades nunca se desenrolem exatamente como estava previsto (PERRENOUD, 1995, p. 51).

Os fatores descritos são decisivos para gerar outro tipo de currículo no espaço escolar, o oculto; aquele que não aparece em diretrizes e nem no planejamento do professor, no entanto é um tipo de currículo que professa o conhecimento que irá ser adquirido em meio às várias práticas em relação às atitudes, condutas, percepções que são vivenciadas tanto no espaço escolar quanto na sociedade de maneira geral. Sendo assim, o currículo oculto contribui para a apreensão de conhecimentos, determinando valores, anseios sem que seja necessário fazer parte dos programas previamente elaborados de currículo. Pensando conforme Sacristán (2000, p. 43),

\footnotetext{
A acepção do currículo como conjunto de experiências planejadas é insuficiente, pois os efeitos produzidos nos alunos por um tratamento pedagógico ou currículo planejado e suas consequências são tão reais e efetivos quando podem ser os efeitos provenientes das experiências vividas na realidade da escola sem tê-las planejado, às vezes nem sequer ser conscientes de sua existência. É o que se conhece como currículo oculto.
}

Ao explicitar o currículo prescrito, o currículo real e o currículo oculto como possibilidades para que o conhecimento aconteça em diferentes rumos e caminhos, percebemos que as inquietações acerca do currículo necessitam que este instrumento seja tomado como algo não

\begin{tabular}{l|c|c|c|c|c|c} 
(C) Rev. Educ. Perspec. & Viçosa, $M G$ & v.8 & n.1 & p.89-105 & jan./abr. 2017 & eISSN 2178-8359 \\
\hline
\end{tabular}


estático, que está sempre em construção. É com base nesta premissa, como já explicitado em nossa pesquisa, que são selecionados saberes e práticas construídos em contextos sociais, políticos, culturais, econômicos e pedagógicos e que necessitam ser trabalhados no espaço escolar.

Outro aspecto que nos chamou atenção foi a confusão teórica entre o sentido de currículo e de Projeto Político Pedagógico quando os professores representaram, assim, o conceito de currículo:

É o projeto político pedagógico da escola (Professor da Educação Infantil).

É um meio em que a escola se orienta e organiza (Professor da Educação Infantil).

Meio pelo qual a escola se organiza (Professor dos Anos Iniciais do Ensino Fundamental).

Construção a partir do PPP (Professor dos Anos Finais do ensino fundamental).

Organização da escola para poder trabalhar (Professor do Ensino Médio).

Organização das propostas que devem ser desenvolvidas na escola (Professor do Ensino Médio).

Os $12 \%$ dos docentes que expressaram que currículo é uma maneira de organização da escola, ou sendo mais diretos, dizendo que se tratava do PPP escolar, de certa maneira, relacionam o Projeto Político Pedagógico como sendo propriamente o currículo, uma vez que é sabido que o Projeto Político Pedagógico está conectado diretamente com a organização da escola citada pelos docentes. Podemos afirmar que, embora não tenha a magnitude do currículo, o PPP é primordial para a escola; aquele que se responsabiliza pela organização do tempo e do espaço escolar. Desta forma, a finalidade deste dispositivo é propor ações, sempre respaldado por pressupostos arquitetados por toda comunidade escolar. Nesta perspectiva,

\begin{abstract}
O projeto político-pedagógico ao se constituir em processo democrático de decisões preocupa-se em instaurar uma forma de organização [...] que supere os conflitos, buscando eliminar as relações competitivas, corporativas e autoritárias, rompendo com a rotina do mando impessoal e racionalizado da burocracia que permeia as relações no interior da escola, diminuindo, os efeitos fragmentários da divisão do trabalho que reforça as diferenças e hierarquiza os poderes de decisão (VEIGA, 1995, p. 13).
\end{abstract}

Isto posto, o PPP é um meio de materialização do currículo, uma vez que, para obter este planejamento democrático na escola, é necessário um entendimento prévio das concepções teóricas e curriculares que estabelecem a educação. Pensando conforme Gadotti (2000), não conseguimos arquitetar um projeto sem uma orientação política, teórica, isto é, um norte que nos faça compreender a importância social, econômica, política, cultural e pedagógica para ser refletido no PPP. Quando percebermos estas narrativas presentes no currículo, tanto de modo explícito quanto implícito, entenderemos que estas

n.1 1 p.89-105


corporificam noções particulares sobre conhecimento, sobre formas de organização da sociedade, sobre os diferentes grupos sociais. Elas dizem qual conhecimento é legítimo e qual é ilegítimo, quais formas de conhecer são válidas e quais não o são, o que é certo e o que é errado, o que é moral e o que é imoral, o que é bom e o que é mau, o que é belo e o que é feio, quais vozes são autorizadas e quais não o são (SILVA, 1995, p. 19).

Sendo assim, ao apresentarmos o pensamento dos professores conferindo ao currículo a função do Projeto Politico Pedagogico ou uma forma de organização da escola, cremos que estes docentes necessitam ver o currículo além desta reflexão uniforme, em que atribuem ao currículo apenas como uma organização formal e ou burocrática da escola.

Diante desses fatores, cremos que a educação possui distintos objetivos quando pensamos na formação do ser humano, consequentemente, ao ponderarmos acerca de um currículo para a formação humana, entendemos que deve ser aberto para a apreensão de conhecimentos significativos, conhecimentos que proporcionem ao sujeito condições de estranhar o mundo à sua volta e não se pautar em uma visão reducionista de sua formação.

Isto posto, explicitamos, em nossa próxima análise, duas visões opostas evidenciadas pelos professores, uma que vê este instrumento apenas como uma referência ou formação pessoal e outra visão mais ampla, que apresenta uma noção mais coerente de currículo com os propósitos da educação e da formação humana.

Em um primeiro momento, constatamos que $8 \%$ dos docentes emitiram um juízo de currículo reduzido a um documento que apenas especifica dados do indivíduo quanto à sua formação profissional ou acadêmica. Como pode ser notado nos discursos subsequentes:

Entendo como um documento que consta os dados profissionais, bem como formação de um cidadão (Professor da Educação Infantil).

Acredito que é toda a bagagem que o aluno soma ao longo de sua vida escolar (Professor da Educação Infantil).

Formação que a escola oferece aos professores (Professor da Educação Infantil).

Nós formamos o nosso currículo no final do nosso curso (Professor dos Anos Iniciais do Ensino Fundamental).

Formação básica que se deve ter (Professor dos Anos Finais do Ensino Fundamental).

Sua vida escolar, cursos e contribuições (Professor dos Anos Finais do Ensino Fundamental).

É o que aprendemos na graduação (Professor do Ensino Médio).

De certa maneira, estes docentes, ao formularem suas representações, qualificaram o currículo em seu sentido etimológico, uma vez que a palavra curriculum é de origem latina e significa curso, trajetória, um caminho da vida que é feito por um indivíduo ou por um grupo de pessoas (SACRISTÁN, 2000). Pensando por este viés, o currículo terá como intuito

\begin{tabular}{l|l|l|l|} 
n.1 & p.89-105 & jan./abr. 2017 & eISSN 2178-8359 \\
\hline
\end{tabular}


responder justamente às representações que estão explícitas nos discursos dos professores, ou seja, será um resumo dos dados pessoais e profissionais do sujeito, com suas aptidões, experiências profissionais e formação acadêmica. Nesta acepção, além de os professores se enquadrarem neste sentido de currículo ao conceituá-lo, fazem com que a educação escolar seja apenas "[...] um percurso (sem reflexão) para os alunos [...], sendo o currículo seu recheio, seu conteúdo, o guia de seu progresso pela escolaridade” (SACRISTÁN, 2000, p. 12).

Ao ser reduzido a um documento que somente informa dados pessoais e profissionais, temos uma compreensão de que este sentido de currículo irá ser, consequentemente, um modo de mostrar o indivíduo como um ser empregável, uma quase mercadoria para os postos de trabalho, e as instituições formadoras, por sua vez, serão transformadas em um espaço de treinamento que prepara esta mão de obra. Porém reconhecemos que, se for refletido com consciência crítica, é possível perceber o currículo como uma trajetória, um caminho a ser percorrido, já que este documento também expõe em sua construção "histórias da vida", histórias que se relacionaram a percursos, caminhos que foram trilhados e que ficou documentado, sejam na educação ou na sociedade como um todo.

À medida que temos ciência deste processo, veremos o currículo como um percurso que nos proporciona ponderar criticamente sobre nós mesmos, perceber nossa caminhada histórica como indivíduo e sociedade, com nossas contradições, desigualdades, especificidades. Assim, muito mais que estabelecer o significado do currículo apenas como dados que servirão para uma qualificação para o trabalho, compreendemos que este tem que possuir um significado amplo, que oportuniza o desenvolvimento do ser humano nos vários âmbitos da sociedade. Reforçando este pensamento, Silva (2010) relata que o currículo pode equivaler a um conjunto de experiências que o espaço educacional apresentará aos sujeitos, mas que também pode ser um componente de transformação ou conservação das relações de poder, uma vez que a formação proporcionada por este espaço representa um tipo de conhecimento que é determinado pela construção do currículo. Concordamos com Silva (2010, p. 150) quando afirma que:

O currículo é lugar, espaço, território. O currículo é relação de poder. O currículo é trajetória, viagem, percurso. O currículo é autobiografia, nossa vida, curriculum vitae: no currículo se forja a identidade. $\mathrm{O}$ currículo é texto, discurso, documento. $\mathrm{O}$ currículo é documento de identidade.

Portanto, o saber propiciado pelo currículo na formação humana não deve ser percebido apenas como uma conquista individual, mas como uma oportunidade de constituição pessoal e que irá se refletir na vida social. Destarte, a formação humana tem que ser percebida em sua totalidade, isto significa pensar em um sentido de currículo que incorpore nossas 
inquietações. É, ao mesmo tempo, uma circunstância que nos mantém "mobilizados para o desenvolvimento dos processos de aprendizagens, para conhecermos e para sermos desafiados para o uso do conhecimento" (SANTIAGO, 2006, p. 77). Este pensamento, que traduz um sentido amplo de currículo, guardada as devidas proporções, ficou evidente no relato de $8 \%$ dos professores pesquisados. Está claro nos seguintes discursos:

O Currículo não é imparcial, é social e culturalmente definido, reflete uma concepção de mundo, de sociedade e de educação, implica relações de poder, sendo o centro da ação educativa (Professor da Educação Infantil).

Faz parte do processo de aprendizagem, deve ser flexível e adaptável (Professor dos Anos Iniciais do Ensino Fundamental).

É o que sustenta a escola (Professor dos Anos Finais do Ensino Fundamental).

O currículo é o encaminhamento, a normatização dos nossos trabalhos é estar num constante diálogo, o nosso norte pra não banalizar o nosso trabalho, ele fundamenta nossas questões, dá encaminhamento pra possíveis pesquisas, ele faz com que o mais importante hoje quando se olha o currículo é levantar os questionamentos: Por que aquele conteúdo? Por que aquela grade é tão ampla? Ou se não estão suprindo alguns itens, então ele possibilita essas questões que permitem um constante estudo (Professor do Ensino Médio).

Apesar destes discursos apresentarem diferentes maneiras de perceber o currículo, às vezes até de forma concisa, vemos que são significações coerentes quando refletimos acerca deste instrumento, por ser uma construção social, no sentido de encontrar-se diretamente ligado a um contexto histórico, à determinada sociedade. Trata-se, portanto, de um instrumento político-pedagógico que está conectado à ideologia, à estrutura social, à cultura, ao poder e, finalmente, ao fazer pedagógico. Neste sentido, quando a nossa reflexão distingue-se de uma percepção de currículo que está pautada em um ponto de vista restrito e inerte do que seja o saber, proporcionará a constatação de tensões que originam a construção do currículo e que dão sentido a ele, tornando-o um "organismo vivo", flexível e adaptável às distintas realidades e necessidades do sujeito. Assim sendo, o ato de perceber criticamente o conhecimento que dá sentido ao currículo

\footnotetext{
exige uma presença curiosa do sujeito em face do mundo. Requer sua ação transformadora sobre a realidade. Demanda uma busca constante. Implica em invenção e em reinvenção. Reclama a reflexão crítica de cada um sobre o ato mesmo de conhecer, pelo qual se reconhece conhecendo e, ao reconhecer-se assim, percebe o 'como' de seu conhecer e os condicionamentos a que está submetido seu ato. [...] Conhecer é tarefa de sujeitos [...]. E é como sujeito, e somente enquanto sujeito, que o homem pode realmente conhecer (FREIRE, 1992, p. 27).
}

Para se inserir neste processo, é necessário um "desligamento" de pensamentos ambíguos e simplificados que restringem o currículo a um percurso que determina somente qualificações individuais, com conteúdos disciplinares pré-determinados e metodologias desconexas da realidade. O norte para onde aponta o currículo é abrangente, sempre estará compreendido

n.1 1 p.89-105


por intenções, é um processo resultante da convergência de distintas ações praticadas por diferentes atores e em períodos igualmente distintos.

$\mathrm{Na}$ consecução de tais pressupostos, é necessária uma consciência crítica que destaque interesses e conhecimentos almejados pelos sujeitos que compartilham a educação escolar e desejam uma formação completa, que envolve diversos âmbitos da sociedade. Esta é uma maneira de "viver" o currículo na escola, isto é, ação e reflexão pela práxis, em que "[...] as práticas e as palavras têm sua história e refletem as atividades nas quais forjaram os significados que arrastam até nós, projetando-se em nossas ações e pensamentos, na forma de dar sentido à experiência”. (SACRISTÁN; PÉREZ, 1998, p. 11).

Orientado por esta perspectiva, o currículo é um elemento articulador central, que "sustenta" o conhecimento escolar, já que está envolvido, entre outros fatores, por determinações sociais, políticas e pedagógicas em relação ao conhecimento educacional e, assim, necessita ser pensado criticamente para que sejam desvendados os conhecimentos que são cercados de valores, disposições, intencionalidades e que constantemente são avaliados como legítimos. Cremos que o entendimento do professor acerca do currículo de forma global irá proporcionar ações voltadas à investigação, explicitando por quem foi estabelecida esta validade e legitimidade do conhecimento e até que ponto é verdadeiro e interfere em sua formação e em seu trabalho. Logo, "a ação do ensino não pode ser considerada como um mero recurso instrumental, uma técnica para conseguir metas abstratamente, porque essas metas não podem ser qualquer fim” (SACRISTÁN, 1999, p. 44).

Desta forma, compreender o currículo no contexto da sociedade contemporânea, que é perpassada por pretensões políticas, econômicas e sociais contraditórias, requer uma análise comprometida deste instrumento, a qual pressupõe repensar os fatores que interferem em um bom desenvolvimento tanto da formação quanto do trabalho docente para que ocorra uma compreensão crítica do currículo. Caso isto não seja feito, as acepções mais fundamentais da educação continuarão sendo deliberadas por perspectivas da teoria tradicional do curriculo o que implicará em pensamentos reducionistas que não proporcionarão uma consciência crítica e reflexiva dos sujeitos envolvidos no processo de ensino e aprendizagem no que tange a relação entre educação e sociedade.

\section{CONSIDERAÇÕES FINAIS}

Este estudo aponta que o currículo escolar, no contexto da sociedade contemporânea, necessita ser constantemente refletido e problematizado, por evidenciarmos uma certa 
dificuldade do professor em perceber criticamente os muitos fatores que perpassam este instrumento de formação que é fundamental para o encaminhamento do trabalho pedagógico.

Valendo-nos das representações dos sujeitos de nossa pesquisa, ficou claro que, no contexto atual, os professores se manifestam, com frequência, de maneira distorcida e fragmentada sobre o curriculo, pois tecem discursos acríticos e fragmentados no modo de perceber o curriculo escolar. Acreditamos que muitas dessas representações distorcidas e reducionistas presentes no cotidiano escolar refere-se a não disussão critica do curriculo nos cursos de formação inicial e continuada voltados aos profissionais da educação. Entendemos que, quando não acontece um estranhamento de discursos pautados no conceito e no contexto do curriculo pode-se por internalizar o curriculo apenas numa perspectiva tradiocinal onde o que impera é a reprodução de conhecimento sem levar em consideração o contexto sociopolitico-economico e cultural de uma dada sociedade

Isso traz uma infinidade de prejuízos para a educação e para todos os sujeitos que fazem parte deste processo, porque acontecem perdas que vão desde os conteúdos trabalhados até uma apreensão coerente de conhecimentos políticos, pedagógicos, sociais, culturais, uma vez que esta visão fragmentada e linear contribui para que seja frustrada uma concepção de educação realmente crítica, que não desfigura a realidade. Assim, em seu processo educativo, o homem é incorporado a uma existência intangível e fragmentada, na qual não consegue compreender os acontecimentos que se interpõe entre ele e a realidade.

Entendemos que estas particularidades, nas quais se encontram condicionados um juízo de formação, de trabalho docente e de currículo, fazem parte de um plano neoliberal de educação, em que não temos políticas públicas e educacionais que pensem a educação e o currícilo de maneira séria e comprometida com o contexto social. Não temos um projeto de nação e sim apenas projetos partidários que se empenham, quase que exclusivamente, em instituir uma concepção de nacionalidade sem cidadania (pertencer sem exercer), cujo discurso se direciona apenas à legitimação de uma suposta ordem social, que tem como intuito reforçar ações para criar no sujeito um caráter passivo.

Neste panorama, acontecem pseudas construções "críticas" do currículo, quase sempre com discursos entusiásticos para que aconteça uma formação de professores que seja comprometida com o pedagógico e com o social. No entanto, são discursos que se tornam evasivos, já que a conjuntura neoliberal que assola o país força uma prática docente com atitudes adversas e incompatíveis com o que pregam os documentos oficiais e/ou os bancos dos cursos de licenciatura, nos quais, em raras exceções, os sujeitos não se opõem e não se colocam em posição de enfrentamento ante a imposição de ideias e pontos de vista. Tornouse quase natural o acatamento a hierarquias sem uma reflexão maior. Este é o quadro em que

\begin{tabular}{l|c|c|c|c|c|c|} 
(C) Rev. Educ. Perspec. & Viçosa, $M G$ & v.8 & n.1 & p.89-105 & jan./abr. 2017 & eISSN 2178-8359 \\
\hline
\end{tabular}


regras são efetuadas, são decididos regulamentos e normas que norteiam as ações dos sujeitos e todos estes aspectos foram constatados nas falas dos professores, sujeitos de nossa pesquisa, principalmente quando estes afirmaram, que o curriculo é apenas uma grade curricular que contempla disciplinas e que estas presciam ser trnasmitidas de maneira não contextual, o que implica em uma formação acritica do sujeito aprendente.

Neste sentido, a escola como um todo necessita estranhar o currículo escolar, possibilitando desta maneira, ressignificar o processo de ensino e aprendizagem, buscando, desta forma, o esclarecimento. Para Kant (2005), o esclarecimento acerca do mundo pelo homem requer dele o afastamento do pensamento do outro e assunção ao que lhe dá liberdade de escolha, ou seja, seu próprio pensamento. Somente assim a escola, por meio dos seus profissionais da educação e do curriculo, poderá lançar-se ao mundo do debate para construir alicerces de um novo mundo, que possibilitará entender o contexto da sociedade contemporânea e a formação do sujeito neste cenário configurado pelas incertezas e possibilidades de mudanças e avanços no campo científico, cultural, social, tecnológico e humano. Trata-se de um processo de materialização do reconhecimento de que há formas e alternativas de experiências acadêmicas que vão além de papéis estabelecidos, espaços de ensinar e tempos de aprender presentes nos espaços formativos. Por isso é fundamental os professores contestarem sobre quais conhecimentos pretendem passar? Para quem? Para quê e Como?

Silva (2010, p. 30) defende que, "para as teorias críticas do currículo o importante não é desenvolver técnicas de como fazer o currículo, mas desenvolver conceitos que nos permitam compreender o que o currículo faz".

Essa problematização nos faz perceber a necessidade de termos clareza em relação à visão de mundo, de sociedade e de educação que acreditamos. Portanto, o saber propiciado pelo currículo na formação humana não deve ser visto apenas como reprodução de uma dada ideologia. Nesta perspectiva, queremos chamar à atenção para a necessidade de formação continuada em todos os níveis de educação a fim de que os professores estejam sempre em um movimento de reflexão, de estudo e de discussão sobre as questões relacionadas ao currículo, para que desta forma, se encontrem conscientes de que é preciso ter intencionalidades muito claras na construção do saber sistematizado.

Destarte, ainda como considerações finais, relatamos que deixamos o nosso estudo não como uma verdade absoluta, mas como mais uma maneira de reflexão, em especial da formação, do trabalho docente e do currículo, evidenciando que o ato de ensinar e aprender compreende um contexto além dos muros escolares. Para tanto, é necessária uma junção (consciente e democrática) de vozes que questionem as explicações comuns e reducionistas que desviam os conceitos e funções fundamentais da educação e do curriculo. Essa problemática não se

\begin{tabular}{l|l|l|l|l|l|l} 
(c) Rev. Educ. Perspec. & Viçosa, $M G$ & v.8 & n.1 & p.89-105 & jan./abr. 2017 & eISSN 2178-8359 \\
\hline
\end{tabular}


encerra aqui, muito pelo contrário, abre e desperta nosso interesse na continuidade da investigação acerca do curriculo, pois precisamos tornar este um território a ser contestado e problematizado.

\section{REFERÊNCIAS}

CHIZZOTTI, Antonio. Pesquisa em ciências humanas e sociais. São Paulo: Cortez, 1995.

DUARTE, Rosália. Entrevistas em pesquisas qualitativas. Educar, Curitiba: UFPR, n. 24, p. 213-225, 2004.

FREIRE, Paulo. Pedagogia da esperança: um reencontro com a pedagogia do oprimido. Rio de Janeiro: Paz e Terra, 1992.

GADOTTI, Moacir. Perspectivas atuais da educação. Porto Alegre, Ed. Artes Médicas, 2000.

GIL, Antônio Carlos. Métodos e técnicas de pesquisa social. São Paulo: Atlas, 1999.

KANT, Immanuel. Resposta à pergunta: que é esclarecimento? Textos Seletos. Tradução Floriano de Sousa Fernandes. Petrópolis, RJ: Vozes, 2005.

MCLAREN, Peter. A Vida nas Escolas: uma introdução à pedagogia crítica nos fundamentos da educação. Porto Alegre: Artmed, 1997.

PERRENOUD, Philippe. Ofício de aluno e sentido do trabalho escolar. Porto: Porto Editora, 1995.

PINTO, Tarcísio de Paula. Metodologia para a gestão diferenciada de resíduos sólidos da construção urbana. 1999. 189 f. Tese (Doutorado em Engenharia Civil) - Escola Politécnica da Universidade de São Paulo, São Paulo, 1999.

SACRISTÁN, José Gimeno. O Currículo, uma reflexão sobre a prática. Porto Alegre: Editora Artmed, 2000.

SACRISTÁN, José Gimeno. Poderes instáveis em educação. Porto Alegre: Artmed, 1999.

SACRISTÁN, José Gimeno; PÉREZ GÓMEZ, Ángel I. Compreender e transformar o ensino. Artmed, 1998. 
SANTIAGO, Marlene Ferreira. O efeito da tributação no planejamento financeiro das empresas prestadoras de serviços: um estudo de caso de desenvolvimento regional. 2006. 139f. Dissertação de Mestrado - Universidade de Taubaté, 2006.

SILVA, Rubia da.; Hornburg, Nice. Teorias sobre currículo: uma análise para compreensão e mudança. Revista de divulgação técnico-científica do ICPG, v. 3, n. 10, p. 61-66, jan./jun. 2007.

SILVA, Tomaz Tadeu. Documentos de identidade: uma introdução às teorias do currículo. 3. ed. Belo Horizonte: Autêntica, 2010.

SILVA, Tomaz Tadeu. A produção social da identidade e da diferença. In: SILVA, Tomaz Tadeu (Org.). Identidade e diferença: a perspectiva dos Estudos Culturais. 13 ed. Petrópolis: Vozes, p. 73-102, 1995.

TYLER, Stephen. Post-modern ethnography: from document of the occult to occult document. In: CLIFFORD, James; MARCUS, George. Writing culture: the poetics and politics of ethnography. Berkeley, Los Angeles, London: University of California Press, 1986.

VEIGA, Ilma Passos (Org.). Projeto político pedagógico da escola: uma construção possível. Campinas: Papirus, 1995.

\section{Agradecimentos}

Aos integrantes do Grupo de Pesquisa Currículo e a Práxis Pedagógica: Pressupostos e Implicações no Campo Educacional da Universidade Estadual de Londrina, pelas discussões instigantes e valiosas e pelas diversas contribuições no que tange ao pensar o currículo enquanto um território a ser contestado, possibilitando assim, ressignificar a formação e o trabalho docente enquanto um instrumento de emancipação humana e social.

Ao Departamento de Educação e Programa de Mestrado e Doutorado em Educação da Universidade Estadual de Londrina e a escola estadual localizada na cidade de Londrina, que tornaram possível a realização desta pesquisa. Muito obrigada pelas contribuições e inquietações que vocês provocaram no que concerne às questões que envolvem: currículo, formação e trabalho docente.

À Coordenação de Aperfeiçoamento de Pessoal de Nível Superior (Capes) e ao Conselho Nacional de Desenvolvimento Científico e Tecnológico (CNPq) pelo apoio financeiro que possibilitou a concretização desta pesquisa.

A todos que, direta ou indiretamente, contribuíram para o desenvolvimento deste estudo. 
' Adriana Regina de Jesus Santos - Docente de Graduação e Pós-graduação e Pós doutoranda em Educação na Universidade Federal Fluminense. E-mail: adrianatecnologia@yahoo.com.br

${ }_{\text {ii }}$ Rogerio da Costa - Docente dos cursos de graduação e Pós Graduação da Universidade Federal de Londrina.

Doutor na área de Ciências Sociais. E-mail: adrianar@uel.br

Submetido em: 06-09-2016 - Aceito em: 03-05-2017.

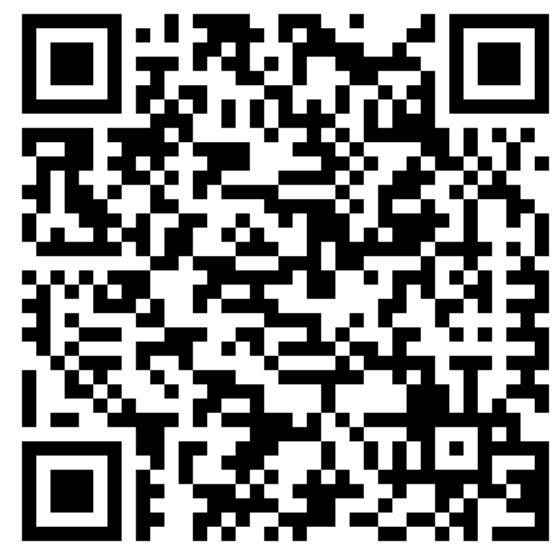

